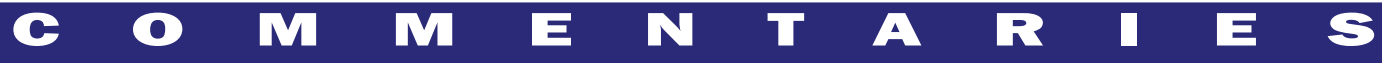

\section{Soft Tissue and Trigger Point Release, Second Edition}

by

Jane Johnson [2019; Human Kinetics; 270 pages; ISBN 978-1-4925-6762-2; US \$44]

\author{
Review by \\ John J. Balletto, BSc, LMT, CKTP ${ }^{\circledR}$ \\ Center for Muscular Therapy, Pawtucket, RI, USA
}

\begin{abstract}
Soft Tissue and Trigger Point Release, 2nd Edition, is a well-organized, clearly written, practical guide to soft tissue manipulation with clients/patients in acute or chronic pain, athletes, and the general population of all ages seeking relief from any soft-tissue generated discomfort. The book is rich with photographs, illustrations, tables, and step-by-step instructions, making protocols easy to follow and execute. It may be a useful addition to the libraries of descriptive manual therapy techniques for massage therapists, chiropractors, osteopaths, and physical therapists, but falls short on current discussions in the literature on trigger point identification, pain, and pain science. $(1,2,3,4)$

The first edition, published in 2009, was designed as a stand-alone text or as a support to ongoing professional development workshops in soft-tissue therapies. This second edition, according to the author, fulfills the same purpose and includes:
\end{abstract}

- 153 new photographs

- 21 anatomical illustrations

- more photographic examples of hands-on techniques

- a new section on deactivation of trigger points

- new sections on applications of soft tissue release on specific musculature

- more tips and helpful hints in each chapter

The book is organized into four distinct parts: Getting Started with Soft Tissue Release; Soft Tissue Release Techniques; Applying Soft Tissue Release; and Soft Tissue Release Programmes. The author refined these techniques during years of her clinical massage therapy practice. Within each part are several chapters that include summaries and "quick" review questions on content covered. Answers to each chapter's quick questions, supporting references, and citations are found at the end of the book.

Part 1 defines "soft tissue release" (STR) as an advanced massage technique used to assess and stretch the soft tissues of the body. It targets specific areas of tension, usually within an individual muscle, for the purposes of reducing areas of tension within a muscle or to target a specific muscle within a larger muscle group. The author claims that it has proven useful in the treatment of certain medical conditions by stimulating tissue repair. There are no references, though, to support these claims. The author does, however, state that more specific research is needed, and that these techniques and claims are based upon her many years of clinical practice. There are sections identifying populations who would benefit from STR, how STR works, where and when to perform STR, and the benefits of STR.

A shortfall of this section is the discussion of the relationships of STR and trigger points. It is based on the work of Davis ${ }^{(5)}$ and Simons and Travell ${ }^{(6)}$ and is quite dated. There is much controversy on the etiology of trigger points, the clinical presentation of trigger points and their related symptoms, and even question of the actual existence of trigger points. ${ }^{(7,8,9,10)}$ While the author mentions some of the recent scientific discussion on these topics, there are no current references cited that indicate any change or variations in the presentation of STR techniques, and no discussion as to the impact these discussion may have on the further development and/or their recommended use. ${ }^{(4,11,12)}$

In Part II, three classifications of STR are clearly defined and presented: passive, active-assisted, and active. Each is the subject and focus in a dedicated chapter. Johnson thoroughly explains, in text and with supporting photographs, proper technique execution, practitioner hand and body positioning, key tissue holding, and movement patterns. In each chapter, situations in which STR can be most useful and/or successful are highlighted, as well as the use of massage tools when appropriate, good client consultation and communication, and, of course, safety issues and concerns.

Part III provides detailed information on the application of STR techniques to specific muscles and/or muscle groups. Each chapter starts with a table summarizing the specific muscles covered and the specific STR techniques to which they likely respond. Additionally, text and photographs follow and identify commonly presented trigger point sites within these muscles or muscle groups. Each chapter presents STR 
techniques applicable to select treatment or targeted area, both for use in the clinic or at home for self-care by clients and practitioners alike.

The title of Part IV is "Soft Tissue Release Programmes" and discusses the client consultation process and session plan design. Topics presented include the type of initial questions practitioners may wish to ask, examples of intake/initial visit forms, common assessment tools (both objective and subjective), and other types of documentation that may be used. There are four detailed case presentations that can be helpful to understand how historical and medical information can be integrated into a design or program of care that will help practitioners best meet the needs and expectations of their clients using STR techniques contained in this book.

While the text is a useful manual and reference for practitioners, and the techniques demonstrated may - and oftentimes do-yield positive outcomes, some of the definitions, terminology, and purported mechanisms of action are a bit outdated. The question of whether or not "trigger points" actually exist and, if they do, what exactly are they - a structural, biochemical, electrical or physiological phenomenon - is a frequent topic debated in the literature today. Johnson often mentions that massage and stretching can "deactivate" trigger points, yet never fully explains the mechanisms involved in how these interventions "deactivate" or change their activity or symptoms.

Johnson uses terminology very common in the professional vernacular that may not be the best descriptors of what is actually being performed. For example, she speaks of "locking" tissues when point-specific ischemic pressure is exerted. The term "release" is used frequently, and can have multiple meanings and interpretations. While I do not question that the techniques promoted by Johnson elicit changes in the soft tissues of the body, she never clearly describes what is meant by "release". Additionally, the concept of "stretch" is always subject to healthy debate. What is actually "stretching" if "stretch" is actually occurring? While seasoned practitioners may understand or interpret these terms - or have their own understanding, interpretation, and use of these terms - the text does not give reasonably documented explanations that can be shared with other practitioners and clients that are universally accepted and/or applied. This is a challenge of the profession at large and not unique to this text.

All being said, Soft Tissue and Trigger Point Release may be helpful to practitioners unfamiliar with the combination of structured touch in combination with movement. Johnson's techniques are a combination of what others in the profession may call variations of myofascial release, active or passive engagement techniques, or neuromuscular therapies. The technique descriptions are detailed to assist the inexperienced practitioner and specific enough for the more advanced practitioner to address subtleties in soft-tissue dysfunction. This is a "how-to" book, driven by technique application, with passing references to client objectives and goals. However, if you are looking for latest science to support and guide your work, this is not the book for you.

\section{COPYRIGHT}

Published under the CreativeCommons AttributionNonCommercial-NoDerivs 3.0 License.

\section{REFERENCES}

1. do Nascimento JDS, Alburquerque-Sendín F, Vigolvino LP, Oliveira WF, Sousa CO. Inter- and intraexaminer reliability in identifying and classifying myofascial trigger points in shoulder muscles. Arch Phys Med Rehabil. 2018;99(1):49-56.

2. Kumbhare DA, Elzibak AH, Noseworthy MD. Assessment of myofascial trigger points using ultrasound. Am J Phys Med Rehabil. 2016;95(1):72-80.

3. Fernández-de-las-Peñas C, Dommerholt J. Myofascial trigger points: peripheral or central phenomenon? Curr Rheumatol Rep. 2014;16(1):395.

4. Money SJ. Pathophysiology of trigger points in myofascial pain syndrome. J Pain Palliat Care Pharmacother. 2017;31(2): $158-159$.

5. Davis C. The trigger point therapy workbook: your selftreatment guide for pain relief, 2nd ed. Oakland, CA: New Harbinger Publications Inc.; 2004.

6. Simons DG, Travel JG, Simons LS. Travel and Simons'myofascial pain and dysfunction: the trigger point manual. Vol 1: Upper half of body, 2nd ed. Balltimore, MD: Lippinott Williams \& Wilkins; 1999.

7. Quintner JL, Bove GM, Cohen ML. Response to Dommerholt and Gerwin: Did we miss the point? J Bodyw Mov Ther. 2015;19(3):394-395.

8. Dommerholt J, Gerwin RD. A critical evaluation of Quintner et al: missing the point. J Bodyw Mov Ther. 2015;19(2):193-204.

9. Rathbone A, Henry J, Kumbhare D. Comment on: A critical evaluation of the trigger point phenomenon. Rheumatology (Oxford). 2015;54(6):1126-1127.

10. Gerwin R. Trigger point diagnosis: at last, the first word on consensus. Pain Med. 2018;19(1):1-2.

11. Sadria G, Hosseini M, Rezasoltani A, Bagheban A, Davari A, Seifolahi A. A comparison of the effect of the active release and muscle energy techniques on the latent trigger points of the upper trapezius. J Bodyw Mov Ther. 2017;21(4):920-925.

12. Sohns S, Schnieder K, Licht G, von Piekartz H. Manual Trigger point therapy of shoulder pain: Randomized controlled study of effectiveness. Schmerz. 2016;30(6):549-559.

13. Quintner JL, Bove GM, Cohen ML A critical evaluation of the trigger point phenomenon...Rheumatology (Oxford). 2015 Mar;54(3):392-9.

Corresponding author: John J. Balletto, BSc, LMT, CKTP $^{\circledR}$, Center for Muscular Therapy, 545 Pawtucket Ave., Suite A116, Pawtucket, RI, USA 02860-6046

E-mail: johnballetto@me.com 